\title{
Study on the in Vitro Degradation Behavior of Commercial Zn- 4\% Al-Sr Alloy for Biomedical Applications
}

\author{
Yang Liu ${ }^{1,3,4}$, Zhongyi Yin ${ }^{1}$, Yue Liu ${ }^{1}$, Cong Geng ${ }^{1,3}, X u$ Chen $^{2, *}$, Junrui X ${ }^{1, *}$ and Jinfeng Peng ${ }^{1}$ \\ ${ }^{1}$ School of Mechanical Engineering, Xiangtan University, Xiangtan 411105, China \\ ${ }^{2}$ School of Materials Science and Engineering, Xiangtan University, Xiangtan 411105, China \\ ${ }^{3}$ Key Laboratory of welding robot and application technology of Hunan Province, Xiangtan \\ University, Xiangtan411105, China \\ ${ }^{4}$ Engineering Research Center of Complex Tracks Processing Technology and Equipment of Ministry \\ of Education, Xiangtan University, Xiangtan41105, China \\ *E-mail:chenxusun@163.com,xujunrui_hit@163.com
}

doi: $10.20964 / 2018.02 .43$

Received: 29 August 2017 / Accepted: 8 December 2017 / Published: 28 December 2017

\begin{abstract}
$\mathrm{Zn}$ and $\mathrm{Zn}$-based alloys have been recognized as potential biodegradable materials, due to their proven biocompatibility and lower corrosion rates compared to $\mathrm{Mg}$ alloys. However, pure $\mathrm{Zn}$ has poor mechanical properties while $\mathrm{Zn}-4 \mathrm{wt}$.\% $\mathrm{Al}$ alloy $(\mathrm{Zn}-4 \mathrm{Al})$ degrades in a nonuniform manner. In this study, Sr was used as a promising alloying element to improve the uniform corrosion properties of $\mathrm{Zn}-$ 4Al alloy. Microstructure and in vitro degradation behavior of $\mathrm{Zn}-4 \mathrm{Al}$ alloys with addition of different concentrations of $\mathrm{Sr}(0-0.15 \mathrm{wt} \%)$ were systematically investigated. Increasing $\mathrm{Sr}$ addition progressively decreased the volume fraction of primary $\eta-Z n$ phase and progressively increased the $(\beta+\eta)$ lamellar eutectic morphology. The alloy with $0.1 \mathrm{wt} \% \mathrm{Sr}$ displayed the best corrosion resistance. Most importantly, the $\mathrm{Zn}-4 \mathrm{Al}-0.1 \mathrm{Sr}$ alloy exhibited a more uniform corrosion mode in Hanks' solution, which could reduce stress concentration and rapid reduction in the mechanical integrity.
\end{abstract}

Keywords: Biodegradable metals; Zn-based alloys; strontium; corrosion behavior

\section{$\underline{\text { FULL TEXT }}$}

(C) 2018 The Authors. Published by ESG (www.electrochemsci.org). This article is an open access article distributed under the terms and conditions of the Creative Commons Attribution license (http://creativecommons.org/licenses/by/4.0/). 